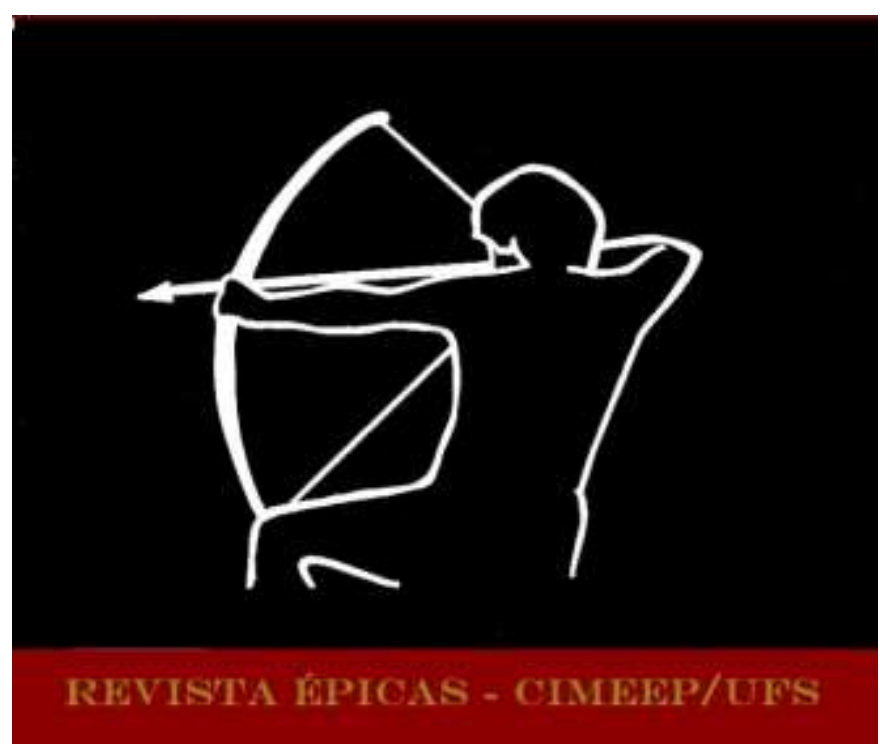

SANTOS, César de Oliveira; PARENTE, Monique Martins. Selva o(culta): o epos e a jornada mítica em Los Reinos Dorados. In: Revista Épicas. Ano 5, n. 9, Jun 2021, p. 44-53. ISSN 2527-080-X. DOI: http://dx.doi.org/10.47044/2527-080X.2021v94453

\title{
SELVA O(CULTA): O EPOS E A JORNADA MÍTICA EM LOS REINOS DORADOS SELVA O(CULTA): EL EPOS Y LA BÚSQUEDA MÍTICA EN LOS REINOS DORADOS
}

\author{
César de Oliveira Santos ${ }^{1}$ \\ Universidade Federal de Sergipe (UFS) \\ Monique Martins Parente ${ }^{2}$ \\ Universidade Federal de Sergipe (UFS)
}

RESUMO: Este artigo apresenta uma análise da epopeia Los Reinos Dorados (2007), do escritor boliviano Homero Oliva. Partindo da constatação de que o texto épico em foco possui fortes traços líricos ao mesmo tempo em que relata um retorno do eu-lírico/narrador a sua ancestralidade, propõe-se uma leitura mítico-histórica da obra: mítica porque parte de elementos simbólicos do texto e histórica em função do debate sobre os povos originários provocado nesse retorno ao passado. Para isso, o conceito de herói mítico de Joseph Campbell (1949) torna-se crucial, pois nos permite ver, na busca identitária do eu-lírico/narrador de Los Reinos Dorados, o percurso a ser cumprido pelo herói de natureza mitológica, segundo o autor estadunidense. Além disso, também são relevantes os estudos sobre o processo de reterritorialização dos povos originários, a exemplo de Monarca (2017) e Ortiz (2011), uma vez que a grande interpretação a que se chegou da jornada mítica do eu-lírico/narrador de Los Reinos Dorados é a de que, por meio do canto, seu povo e sua cultura resistem.

Palavras-chave: Epopeia; Mito; Povos originários; Los Reinos Dorados; Homero Oliva.

RESUMEN: Este artículo presenta un análisis de la epopeya Los Reinos Dorados (2007), del escritor boliviano Homero Oliva. Partiendo de la observación de que el texto épico enfocado tiene fuertes marcas líricas mientras también habla de un retorno del yo lírico/narrador a su ascendencia, se propone una lectura mítico-histórica de la obra: mítica porque parte de elementos simbólicos del texto e histórica en función del debate sobre los pueblos originarios suscitado en este regreso al pasado. Para ello se torna crucial el concepto de héroe mítico de Joseph Campbell (1949), que permite ver en la búsqueda de la identidad del yo lírico/narrador de Los Reinos Dorados el camino a seguir por el héroe de carácter mitológico, según al autor americano. Además, también son relevantes estudios sobre el proceso de reterritorialización de los pueblos originarios, como Monarca (2017) y Ortiz (2011), ya que nuestra gran interpretación

\footnotetext{
${ }^{1}$ Doutorando do Programa de Pós-Graduação em Letras da Universidade Federal de Sergipe. E-mail: cesaroliveira@academico.ufs.br. ORCID: https://orcid.org/0000-0002-1925-5084.

${ }^{2}$ Mestranda do Programa de Pós-Graduação em Letras da Universidade Federal de Sergipe. E-mail: moniqparente@gmail.com. ORCID: https://orcid.org/0000-0003-4108-7045.
} 
de la búsqueda mítica del yo lírico/narrador de Los Reinos Dorados es que, a través de la poesía, su gente y su cultura resisten.

Palabras-clave: Epopeya; Mito; Pueblos originarios; Los Reinos Dorados. Homero Oliva.

\section{Considerações iniciais}

A obra pós-moderna boliviana Los Reinos Dorados $(2007)^{3}$ se inicia revelando, em sua dedicatória, a preocupação central de Homero Carvalho Oliva: salvaguardar origens e legado, isto é, preservar a história ancestral e exaltar o que chama de antiga cultura. Nesse processo, ocorre o reencontro com o self e manifestam-se aspectos basilares da epopeia, posto que os versos permitem entrever a vivência cultural do eu-lírico/narrador e o acervo mítico a que este recorre, guiado pelo pai, para compor a matéria épica do poema. Inicialmente dotados do pluriculturalismo e do multilinguismo característicos das populações amazônicas, os povos originários da Bolívia foram historicamente condicionados forçosamente à castelhanização e à cristianização, o que culminou com o não lugar das línguas e saberes tradicionais.

No século XVI, quando ocorreu a invasão espanhola, os territórios do atual Estado Plurinacional da Bolívia integravam o Império Inca, Tawantinsuyu (UNASUR, 2017, p. 125). Com a colonização, adveio a imposição de preceitos e valores ocidentais em detrimento da cultura originária boliviana, promovendo a distinção étnico-racial e agrilhoando os povos tradicionais a relações de dominação e exploração que alcançaram os dias atuais. Outrossim, a hegemonia dos colonizadores sobre os indígenas foi marcada pela demonização dos ritos e costumes locais, de modo a imprimir a visão de mundo colonial e eurocêntrica retratada na fala do padre madrilenho Diego Francisco Altamirano:

En este pues ardiente clima comenzaba el demonio a abrazar a estos infieles, en aquellos vestidos con paños apacentaba sus desnudas racionales bestias. $Y$ estas espesas montañas ocultaban montaraces estos hombres brutos, sin gobierno, sin ley, sin política y lo más sin Dios [...] Gente en fin sin cabeza, sin premio a la virtud, sin castigo al vicio. Bien fue menester que Dios les diese legislador en nuestro Monarca, para que supiesen que eran hombres. (ALTAMIRANO, 1891, p. 49, apud MOYA, 2014, p. 43-44)

Esse quadro evidencia-se no estudo de Victor Hugo Limpias Ortiz (2011) sobre as missões jesuíticas em Moxos, região originalmente habitada por povos de planícies e florestas tropicais da América do Sul. As organizações sociais incluíam nômades que viviam da caça e da pesca, mas também sociedades sedentárias relativamente complexas e capazes de conduzir construções residenciais e a agricultura. $\mathrm{O}$ autor afirma que "la evangelización jesuítica implicó un radical reemplazo de los sistemas mítico-religiosos premisionales, en un proceso simultáneamente catequizador y civilizador, que transformó la vida y la cosmovisión de miles de indígenas que vivieron en las reducciones de la Misión de Moxos" (ORTIZ, 2011, p. 289).

Essa problemática impulsiona a matéria épica de Los Reinos Dorados, cujos versos recorrem à memória mítica ancestral, histórica e testemunhal para confrontar tentativas de silenciamento das línguas e saberes tradicionais bolivianos. A epopeia retrata a busca pelo resgate e reterritorialização cultural, ao corporificar a imagética e rituais de povos cujo surgimento precede a criação do Estado Plurinacional da

\footnotetext{
${ }^{3}$ Apesar de haver uma tradução para o português, optamos por manter a versão original em espanhol.
} 
Bolívia e que se conectam a Beni, berço de Homero Carvalho Oliva. Assim, o panteão indígena se manifesta no percurso poético em referências ao grande Tigre, senhor dos animais do bosque, ou o Jichi, amo dos rios e mananciais, dentre outras figuras míticas que atuam como guardiãs do limiar para a selva.

Lucy Jemio Gonzales, pontuando relatos colhidos para o projeto "Difusión de los relatos de la tradición oral boliviana, con énfasis en mitos y cuentos", explicita que "Los Jichis son, pues, reconocidos como dioses, con los cuales la gente mantiene relaciones de respeto, normadas por prescripciones y prohibiciones ancestrales" (2011, p. 27). A cultura originária concebe a natureza como lugar do sagrado, cujas manifestações remetem a ritos como os de iniciação e de travessia. Esse espaço, tradicionalmente sob o domínio de seres mitológicos, é permanentemente ameaçado pelo desenvolvimentismo que priorizou a expansão e urbanização de cidades seguindo o modelo europeu, em detrimento das sociedades indígenas.

Partindo dessa premissa, Los Reinos Dorados entrecruza o plano real e o maravilhoso sob a ótica de um eu-lírico/narrador que se reconhece descendente da cultura originária e, como receptáculo do sagrado ancestral, é convocado a contrapor-se aos saberes coloniais que buscam deslegitimá-la. Assim, tomando os sonhos como caminho para o universo mítico, o eu-poético/narrador encontra-se com o pai, em uma jornada de (re)visitação e ressignificação mítico-histórica, a fim de confrontar a descorporalização e a desterritorialização cultural dos povos tradicionais. Contudo, mais do que imergir oniricamente em memórias e percepções tradicionais, dos primórdios de ascendência étnica até o momento atual, a travessia requer como ato primordial trazer à luz elementos e concepções anteriormente representados a partir da concepção dos exploradores.

Apresenta-se, dessa maneira, a aproximação entre os ritos de iniciação, separação e retorno identificados em Los Reinos Dorados e as etapas do percurso a ser cumprido pelo herói mítico descrito por Joseph Campbell. Ademais, o encontro com o pai, que corporifica a face ancestral, revela o processo de individuação: "Mi padre / extiende su brazo / y abriendo su puño / sopla la palma de su mano / dejando escapar en ligera brisa / fabulosas imágenes que se pierden en el aire" (OLIVA, 2018, p. 15). Carl Jung (2014, p. 70) explicita que "en cuanto a la saliva, se trata de la substancia que, según la concepción primitiva, contiene el mana personal, la fuerza vital, mágica, sanadora. Y en cuanto aliento, es el zoho; en árabe, ruj; en hebreo, ruaj; en griego, pneuma, viento y espíritu".

A epopeia, então, compõe um plano tríplice: histórico, mítico e pessoal. Em sua trajetória, o eulírico/narrador assume a representação de um coletivo: os povos tradicionais da Bolívia, compreendidos também enquanto povos amazônicos. Para Christina Ramalho (2020, p. 272), trata-se de "uma viagem de resgate em que o herói épico duplo é também metonímico de toda a América, visto que diferentes espaços fluviais ganham a dimensão do rio Amazonas, quando o pai explica ao filho o motivo de ter vindo, em sonho e voz". Desse modo, o poema atua como condutor da resistência cultural e propagador de saberes decoloniais, numa jornada mítica que se inicia na selva e retoma valores ancestrais naturalistas, em contraposição aos padrões de dominação e exploração socialmente impostos aos povos originários. 
Segundo Claudia Rodríguez Monarca (2017, p. 20), “la imagen y la identificación del río con los sujetos poéticos constituyen, sin lugar a dudas, la filiación que permea la literatura amazónica". Este estudo, então, se propõe a analisar os aspectos mítico-simbólicos que, aliados ao contexto histórico, estruturam Los Reinos Dorados. Acredita-se que, a partir do cruzamento teórico entre os estudos épicos e a mitocrítica, é possível traçar um diálogo entre a imagética das culturas originárias bolivianas e algumas questões socioculturais contemporâneas presentes na epopeia. Este artigo não tem, porém, a pretensão de esgotar o tema proposto a partir da obra de Homero Carvalho Oliva ou mesmo de contemplar todas as nuances do mito e da cultura na Bolívia. Pretende-se, aqui, assinalar possibilidades de confluência entre as abordagens teóricas citadas.

\section{Epos e aproximações no mundo comum: origens da jornada mítico-histórica boliviana}

Los Reinos Dorados é uma epopeia que exalta a cultura originária, por meio da (re)visitação e ressignificação de elementos da tradição oral boliviana. A obra se constitui, segundo Christina Ramalho (2020, p. 271), de "85 estrofes, com número de versos e metrificação diversificados, totalizando 472 versos sem rimas, alguns deles deslocados, conferindo movimento às estrofes". Sobressaem-se o mítico-simbólico e o fator histórico, em aproximações que evidenciam os efeitos da colonização espanhola sobre a vida e o legado dos povos tradicionais, constantemente ameaçados pelo silenciamento sociocultural decorrente da dominação europeia. Ao mesmo tempo, o poema evidencia aspectos identitários e o misticismo da Bolívia, apresentando referências aos falantes de línguas arahuacas e ao xamanismo, como nos versos nos quais figuram os tiarauquis.

A obra transparece a relação imanente entre o sujeito épico-lírico e sujeito empírico, posto que Homero Carvalho Oliva, natural de Beni, na Bolívia, permeia sua composição com referências pessoais e aos povos da região: "de esos nuestros antepasados / descienden tus abuelos y abuelas / movimas, moxeños, sirionós, / itonomas, canichanas, cavineños, / chacobos, baures, cayubabas, chimanes / pacaguaras, otuquis, pausernas, yuracarés / y otros muchos otros pueblos / allende el Río de las Amazonas" (2018, p. 39). O eulírico/narrador de Los Reinos Dorados traduz, assim, a face autobiográfica do escritor, cujo pai, Antonio Carvalho, é representado na epopeia como figura elemental e manifestação do sagrado. Percebe-se, pois, a harmonização com o plano histórico e o mítico-simbólico.

O leitmotiv do poema é anunciado na proposição inicial, na primeira estrofe: ir de encontro à descorporalização e ao não lugar cultural dos povos tradicionais da Bolívia. Com os versos "Siente / mi presencia bajo tu piel / y déjame que vuelque en ti / mi alma cargada de recuerdos / Yo seré tus sueños / y habitaré tus palabras / para que juntos contemos / la historia de los Reinos Dorados" (OLIVA, 2018, p. 13), o pai convoca o eu-lírico/narrador com o despertar da percepção sensorial, ativando, por meio deste, a conexão entre a cultura originária e a sociedade contemporânea. Nesse processo, a presença onírica do pai, representação da ancestralidade, coloca-se como via de acesso à identidade e à memória sociocultural boliviana, numa jornada épica que se sobrepõe a saberes coloniais e eurocêntricos. 
A não recusa do eu-lírico/narrador em unir-se ao pai e cruzar o limiar, do plano real para o onírico, no qual se manifesta o mito, expressa a aceitação do convite à jornada e o anseio pela reapropriação do espaço identitário e cultural tradicionais, isto é, a busca pela reterritorialização: "Desperté radiante / pensando que él había vuelto / y el silencio de la madrugada / me recordó que mi padre / habitaba el infinito de los sueños / volví a dormir / y lo busqué ansioso / en el mundo de adentro" (OLIVA, 2018, p. 14). Assim, conforme comenta Claudia Rodríguez Monarca (2017, p. 312), traçando um paralelo com outras produções de Homero Carvalho Oliva, "el sujeto poético amazónico asume el compromiso y el rol de resguardar y transmitir sus memorias, desde las voces polifónicas, por ejemplo, de un narrador de mitos de creación movima en Los reinos dorados".

O herói mítico empreende uma jornada que, para além do heroísmo no plano maravilhoso, propicia o autoconhecimento e a ressignificação característicos da individuação. Isto é, a travessia traduz ciclos da vida e aspectos identitários inerentes ao convívio em sociedade. Joseph Campbell afirma que "el héroe, por lo tanto, es el hombre o la mujer que ha sido capaz de combatir y triunfar sobre sus limitaciones históricas personales y locales y ha alcanzado las formas humanas generales, válidas y normales" (1999, p. 26). A obra coloca-se, então, como instrumento de resistência e de enfrentamento ao silenciamento cultural que historicamente ameaça os povos tradicionais, posto que o eu-lírico/narrador confronta os períodos précolonial e pós-colonial sob o olhar ancestral, e retorna com renovado arcabouço cultural e identitário, atitude que promove a retomada crítico-reflexiva de elementos basilares do contexto sócio-histórico boliviano.

Nos versos "los exploradores cuentan / que estaban en las selvas de Moxos / y eso no es cierto / que lo cierto es / que la selva estaba en los Reinos Dorados" (OLIVA, 2018, p. 15), o sujeito poético invoca acontecimentos anteriores à invasão espanhola e eventos decorrentes da colonização e da política eurocêntrica. Como explicita Edgar Ávila Echazú (1974, p. 15-16), o desenvolvimento social da cultura aymara, uma das originárias e uma das primeiras a figurar no altiplano boliviano e parte do território do antigo Peru, começou em fins do Paleolítico, aproximadamente 12.000 anos a.c. Por sua vez, Mily Crevels e Pieter Muysken (2009, p. 14) afirmam que "Ios pueblos de la Amazonía boliviana entraron en contacto con la sociedad occidental por primera vez en el siglo XVI (1536-1537), cuando las primeras expediciones españolas con exploradores y conquistadores penetraban el área en busca del oro de El Dorado".

A face do herói metonímico se revela, assim, em Los Reinos Dorados, posto que a imersão onírica do eu-lírico/narrador o convoca a uma jornada mítica onde a representação dos povos originários bolivianos alicerça a construção da matéria épica, que Christina Ramalho (2014, p. 38) define como “temática resultante da fusão de duas dimensões, uma real, outra mítica, fruto da atribuição de uma significação mítica ao evento histórico". A autoaniquilação consequente ao cruzamento do limiar, mencionada por Joseph Campbell (1999, p. 89) e caracterizada pela aceitação das provas e evoluções, se reafirma nas proposições que remetem ao mito de origem e assumem a voz poética do coletivo, isto é, enunciam no plural: 


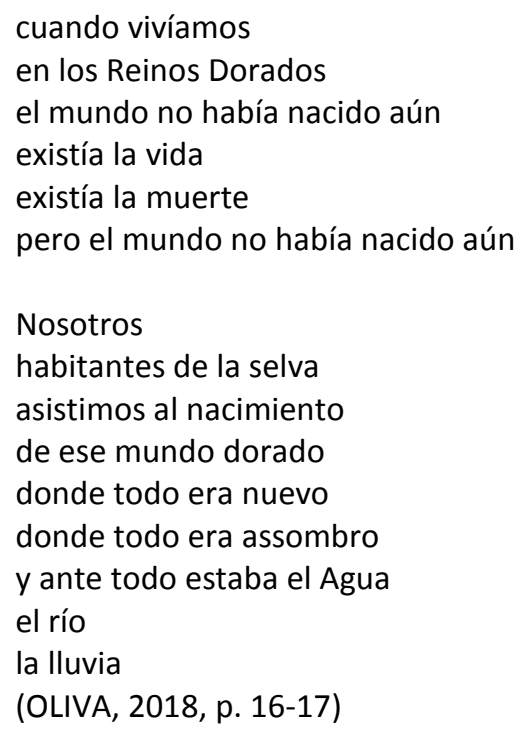

Dessa feita, ante a dominação e exploração impostas pelas práticas eurocêntricas e revisitando aspectos sócio-históricos dos povos originários, o eu-lírico/narrador é conduzido a desvelar problemas enfrentados por seus ancestrais e vivenciados atualmente no mundo comum, isto é, a narrativa parte do plano mítico para delatar questões sociais que se materializam no plano real. Transcorridas as gerações e ante a ameaça do apagamento de sua herança cultural, o sujeito poético empreende a jornada mítica em prol do resgate e da perpetuação de suas tradições. Iniciada a travessia, dedica-se a confrontar elementos e situações decorrentes do comprometimento com a mudança, entendida como processo necessário para ressignificar o acervo cultural tradicional e propiciar a reterritorialização dos povos bolivianos.

\section{Representações mítico-simbólicas do sagrado indígena e do conflito étnico-religioso na Bolívia}

Em análise sobre a poesia amazônica, Claudia Rodríguez Monarca (2017, p. 21) defende que os sujeitos poéticos encontram chaves e estratégias de reterritorialização, como forma de resistência cultural, a partir da experiência e da consciência de desterritorialização e desplazamiento 4 . A pesquisadora considera que "la reterritorialización, siempre en el plano de la escritura, estaría operando mediante dos procesos: la recuperación intracultural (reapropiación de su espacio territorial, cultural y simbólico) y el agenciamiento intercultural (apropiación del espacio ajeno, por parte del sujeto migrante)". Em Los Reinos Dorados, a jornada do eu-lírico/narrador promove o resgate e sacralização de componentes identitários dos povos originários, com representações e valores característicos da cosmovisão indígena. Nesse processo, o poema revisita o percurso mítico-histórico boliviano a fim de desvelar acontecimentos e propiciar a releitura, isto é, ampliar a compreensão acerca dos elementos que constituem e dos que ameaçam a cultura dos povos tradicionais.

\footnotetext{
${ }^{4}$ Cabe destacar os apontamentos de Claudia Rodríguez Monarca sobre "la noción articuladora de territorio (Escobar) y sus derivados, territorialización, desterritorialización y, particularmente, reterritorialización (Deleuze 1997 y Maíz 2010), como procesos concomitantes y fundamentales en los contextos de interferencia cultural" (2017, p.25), e o estudo "Poesía indígena actual: textos que se cantan susurrados en sus lenguas y textos bilingües que se leen", publicado pela pesquisadora em 2017.
} 
O mítico-simbólico-histórico atua, então, como eixo de sustentação entre o conhecimento ancestral e a relação homem-selva-sociedade. O princípio divinizador e de convergência cultural da palavra emerge nos versos "Los nombres / nos eran revelados por / los espíritus protectores de la selva [...] / Los mismos espíritus / crearon la yuca para que / inventemos la chicha y el chivé [...] / cada nación hablaba su propia lengua / pero todos sabíamos que cuando / alguien decía Amarumayu / se refería al Río de las Serpientes" (OLIVA, 2018, p. 18-19, grifo do autor), em que se evidencia a relação de interdependência entre o nome e a conexão com o sagrado indígena, assim como com a integração natureza-sociedade. Graciela Chamorro (2004, p.28), pesquisadora da história e do misticismo guarani, explicita que o nome "es el fundamento fuera del cual nadie puede existir. Por ser llamados con nombres de animales, plantas, astros, fenómenos de la naturaleza o divinidades, los indígenas expresan la profunda identificación, la participación mística de los seres humanos con otros seres de la naturaleza".

Sob esse prisma, o aspecto sagrado e ritualístico dos versos "para cazar y pescar / pedíamos permiso a / los genios tutelares de los lugares" (OLIVA, 2018, p. 20) elucida-se no relato de Erlan Rojas (apud GONZALES, 2011, p. 33): “Nosotros tenemos la costumbre de pedir al Dueño del monte invitándole cigarro y todo lo que producimos y sacamos de la tierra, le invitamos chivé (...) Estoy invitándole a mi amigo, al rey de la selva, para que nos dé ese animal que queremos. [...] Tenemos primero que pedir el animal a su Dueño". Percebe-se o diálogo entre as tradições descritas e etapas da jornada do herói mítico que propiciam a redescoberta do mundo e o renascimento, como o ventre da baleia. O percurso conduz ao problema evocado em Los Reinos Dorados, uma vez que "en todo en el mundo los hombres cuya función ha sido hacer visible en la Tierra el misterio fructificador de la vida, simbolizado en la muerte del dragón, han llevado a cabo en sus propios cuerpos el gran acto simbólico, diseminando su carne, como el cuerpo de Osiris, para la renovación del mundo" (CAMPBELL, 1999, p. 91-92).

Por conseguinte, destaca-se no texto épico a referenciação aos comocois, sacerdotes identificados como os únicos que sabiam os nomes dos tigres. Como ressalta Victor Hugo Limpias Ortiz (2011, p. 295), "varias relaciones coinciden en que los sacerdotes, especialmente los de máxima categoría, debían demostrar haber sobrevivido al ataque del tigre. Esa hazaña sólo se consideraba posible con la protección del dios Tigre invisible, más poderoso que el dios Tigre visible". Após sobreviver ao confronto, o guerreiro deveria obter dos comocois o nome do tigre e adotá-lo como seu. Ademais, era necessário jejuar, passar vários dias em recolhimento e organizar as celebrações a fim de manter a graça dos deuses do animal. Nesse ínterim, cabia às mulheres lavar e purificar os flechadores (UNASUR, 2017, p. 215), de modo que manifesta-se na representação do feminino o encontro mítico com a deusa ou casamento sagrado, como percebe-se nos versos "los hombres bestias / se transformaban em fieras / y en las afueras del pueblo / descansaban después de la cacería / mientras que las bestias / transformadas em hombres / yacían junto a las doncellas del pueblo" (OLIVA, 2018, p. 20).

No âmbito das cosmogonias, mitos e lendas aymaras, Edgar Ávila Echazú (1974, p. 22) afirma que "merecía singulares reverencias, quizá tanto como las ofrendadas a Huerakkocha, la diosa de la tierra: la fértil 
Pachamama". Em Los Reinos Dorados, a existência em comunhão com o meio ambiente e a compreensão da selva como espaço do sagrado promove a união com a Deusa mãe, força geradora da natureza, fonte da vida e provedora da fertilidade, que concede dons para que o herói amazônico alcance o êxito na provação e complete sua jornada. Em consonância, para Campbell (1999, p. 107), a figura mitológica da Mãe Universal promove a associação com os atributos femininos da primeira presença, nutritiva e protetora. $O$ matrimônio

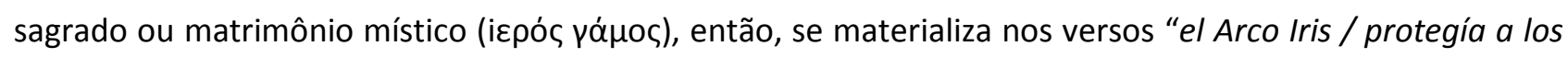
Reinos Dorados / de todos los males y el rocío / fertilizaba a la naturaleza / abrillantando los colores / de las flores y de las plumas de las aves / [...] en los Reinos Dorados / los hombres y la selva éramos uno" (OLIVA, 2018, p. 21-22).

Conforme Campbell (1999, p. 110), em se tratando da linguagem gráfica da mitologia, a mulher representa a totalidade do que se pode conhecer. Desse modo, o herói é aquele que alcança o conhecimento, isto é, que aprende. Segundo o autor, no decorrer da vida e aos olhos do herói, a forma da deusa assume uma série de transformações: "ella lo atrae, lo guia, lo incita a romper sus trabas. Y si él puede emparejar su significado, los dos, el conocedor y el conocido, serán libertados de toda limitación". O equilíbrio entre a cultura originária e a relação homem-selva-sociedade é rompido pela colonização da Bolivia, na qual a imposição dos preceitos ocidentais e do padrão de urbanização europeu se coadunou com a dominação e exploração das sociedades locais. No decorrer da jornada, o sujeito épico-lírico desperta para o legado míticohistórico boliviano, reaproxima-se da cosmovisão indígena e absorve os saberes corporificados no pai, ressignificando-os: "rememorando los muchos nombres / que los viajeros dieron a los Reinos Dorados / mi padre piensa que cada quién vio lo que quería / Llegaron tras las especias" (OLIVA, 2018, p. 25) e "Los llegados de la civilización / nos trajeron la barbarie" (OLIVA, 2018, p. 43). Campbell explicita que

Cuando la misión del héroe se ha llevado a cabo, por penetración en la fuente o por medio de la gracia de alguna personificación masculina o femenina, humana o animal, el aventurero debe regresar con su trofeo trasmutador de la vida. El ciclo completo, la norma del monomito, requiere que el héroe empiece ahora la labor de traer los misterios de la sabiduría, el Vellocino de Oro, o su princesa dormida al reino de la humanidad, donde la dádiva habrá de significar la renovación de la comunidad, de la nación, del planeta o de los diez mil mundos. (CAMPBELL, 1999, p. 179)

A ruptura no padrão colonial e a rememoração dos nomes sagrados, promovidas pelo retorno do pai, vão de encontro à violência ocidentalista e eurocêntrica delatada nos versos "transmutaron la tierra / la Pacha Mama de las altas mesetas / en virgen de todos los cielos / A nuestros lugares sagrados / los volvieron templos cristianos / y a nuestros dioses de la guerra / en santos guerreros de nombres castizos" (OLIVA, 2018, p. 45). Permeado com a memória ancestral, histórica e testemunhal, o plano mítico coloca-se como via para a retomada das tradições indígenas e o consequente resgate dos valores naturalistas. Adentrado o universo onírico e absorvidas as vivências ancestrais, o eu-lírico/narrador dedica-se a contemplar o legado sóciohistórico e mítico-simbólico boliviano visando sua continuidade. Com isso, restaura-se o elo entre os povos tradicionais e a selva, selando o compromisso do eu-lírico/narrador com a perpetuação da cultura originária, 
no que pode ser compreendido como a revitalização do sagrado indígena e caminho para vencer as tentativas de silenciamento das línguas e saberes tradicionais bolivianos. Transformado e renascido, atendendo ao chamado ancestral, o herói eterniza Los Reinos Dorados na literatura amazônica e reapresenta-os ao mundo.

\section{Considerações finais}

Los Reinos Dorados é um relato mítico, histórico e testemunhal sobre o legado boliviano e a ação do tempo e do eurocentrismo sobre a cultura originária. Assim como os ancestrais construíram sobre as árvores "legendarios palacios que se perdían en las nubes", Homero Carvalho Oliva recupera o sagrado e as tradições indígenas numa construção épica que conecta o plano real ao plano maravilhoso, espaço de revisitação e ressignificação da transição entre a sociedade pré-colonial e a contemporânea. A imagética do poema, na qual o apelo ao sensorial é uma constante, intensifica o despertar para elementos identitários e socioculturais, como as línguas arahuacas e ritos xamânicos, ameaçados pela imposição da castelhanização e de valores ocidentalistas que se opõem à cosmovisão indígena. $\mathrm{O}$ eu-lírico/narrador, então, transcende os limítrofes do universo onírico a fim de unir-se ao pai, caracterizado como o guia na jornada pelo acervo mítico-simbólico ancestral.

Nos sonhos, explicita Campbell (1999, p. 97), "encontramos todavia los eternos peligros, las quimeras, las pruebas, los ayudantes secretos y las figuras instructoras, y en sus formas podemos ver reflejado no sólo el cuadro de nuestro presente caso sino también la clave de lo que debemos hacer para salvarnos". Assim, a travessia constitui-se com as memórias mítico-simbólicas e sócio-históricas do pai, representação espiritual dos saberes e tradições originários. O sujeito épico-lírico, em semelhança ao herói mítico descrito por Campbell, depara-se com o caminho de autoconhecimento e compreensão dos ciclos inerentes à vida em sociedade. Provações e inimigos, personificados nos invasores que dessacralizam a selva e impõem relações de dominação e exploração aos colonizados, encontram correspondência ao longo de todo o território amazônico. Dessa feita, reconhece-se o que Christina Ramalho identifica como o herói metonímico de toda a América, posto que a epopeia dialoga com questões sociais que alcançam, além dos ancestrais bolivianos, "otros muchos otros pueblos / allende el Río de las Amazonas / el río mar / el río océano / el río del mundo" (OLIVA, 2018, p. 39).

Ao fim, na iminência do retorno ao plano real, o eu-poético/narrador percebe-se conectado ao universo onírico, receptáculo do sagrado indígena e do legado dos habitantes da selva. Transformado e renascido, o herói é incumbido de transmitir as vozes dos Reinos Dorados escrevendo o que aprendeu, a fim de perpetuar a cultura originária. Nessa missão, a literatura amazônica coloca-se como instrumento de enfrentamento à desterritorialização e de resistência cultural, posto que situa a retomada dos saberes decoloniais como caminho capaz de viabilizar a cada geração escapar aos padrões de dominação e exploração socialmente impostos aos povos tradicionais. Apresenta-se, assim, a via para a reapropriação de espaços ameaçados ou descaracterizados pelos preceitos característicos dos valores coloniais e desenvolvimentistas. Concluída a jornada, "a voz paterna, dissolvendo-se na fumaça, alerta o eu lírico/narrador, seu filho, sobre a 
missão de contar a viagem como forma de alcançar o retorno aos Reinos Dorados, à Grande Casa do Povo, lugar onde o ser humano, afinal, deixa de fazer da natureza 'o outro', para ser ele próprio, natureza também" (RAMALHO, 2020, p. 275)

\section{Referências bibliográficas}

ALTAMIRANO, Diego Francisco (S. J.). Historia de la Misión de los Mojos. Bolivia: Imprenta de El Comercio, 1891. In: MOYA, José Luis Betrán. Como corderos entre lobos hambrientos: La literatura misional jesuita en las fronteras amazónicas del virreinato peruano entre finales del siglo XVII y comienzos del siglo XVIII. Cuadernos de Historia Moderna, Anejo XIII, p. 169-194, 2014.

CAMPBELL, Joseph. El héroe de las mil caras: psicoanálisis del mito. Trad. de Luisa Josefina Hernández. México: Fondo de Cultura Económica, 1999.

CHAMORRO, Gabriela. Teología Guaraní. 1 ed. Quito: Ediciones Abya-Yala, 2004.

CREVELS, Mily; MUYSKEN, Pieter. Lenguas de Bolivia: presentación y antecedentes. In: CREVELS, Mily y MUYSKEN, Pieter (eds.). Lenguas de Bolivia, tomo I, Ámbito Andino, p. 13-26. La Paz: Plural editores, 2009.

ECHAZÚ, Edgar Ávila. Literatura pre-hispánica y colonial. La Paz: Editorial Gisbert \& Cía, 1974.

GONZALES, Lucy Jemio (Org.). Mitos y cuentos chiquitanos, guarayos, movimas y mosetenes. Colección Mitos y Cuentos, tomo 6. La Paz: Universidad Mayor de San Andrés, Facultad de Humanidades y Ciencias de la Educación, Carrera de Literatura, 2011.

JUNG, Carl Gustav; KERÉNYI, Karl. Obra Completa: Civilización en transición. Trad. Carlos Martín Ramírez. Madrid: Editorial Trotta, 2014.

MONARCA, Claudia Rodríguez. Estrategias de reterritorialización en la poesía amazónica contenporánea. Taller de Letras: Santiago, 2017. p. 19-37.

OLIVA, Homero Carvalho. Los Reinos Dorados. Madrid: Amargord Ediciones, 2018.

OLIVA, Homero Carvalho. Los Reinos Dorados. Santa Cruz de la Sierra: Editorial La Hoguera, 2007.

ORTIZ, Victor Hugo Limpias. Lo infernal, lo terrenal y lo celestial en la Misión de Moxos. In: Entre cielos e infiernos. Memoria del V Encuentro Internacional sobre Barroco. Pamplona: Editorial GRISO - Universidad de Navarra/Fundación Visión Cultural, 2011.

RAMALHO, Christina. Estratégia para a leitura da poesia épica. Revista Interdisciplinar, ano IX, v. 21, p.3548, jul./dez. Itabaiana, 2014.

RAMALHO, Christina. Los Reinos Dorados. Epopeia/poema épico. Revista Épicas. Ano 4, Número Especial 3, p. 271-190, nov. São Cristóvão, 2020.

UNASUR. Diversidades culturales: pueblos indígenas de Suramérica. Memoria técnica: Foro de Diversidades Culturales - Pueblos Indígenas de Suramérica, dentro del Proyecto del Atlas de la Diversidad Cultural - Pueblos Indígenas de Suramérica UNASUR. La Paz: UNASUR/Ministerio de Culturas y Turismo de Bolivia, 2017. 